\title{
The Match Between Apache Indians' Culture And Educational Practices Used In Our Schools: From Problems To Solutions
}

Lawrence Ingalls, (E-mail: lingalls@utep.eedu), University of Texas at El Paso

Helen Hammond, (E-mail: hhammond@utep.edu), University of Texas at El Paso

\begin{abstract}
This study examined cultural values and practices of Apache Indian families in regards to child rearing and how culturally responsive our schools' educational practices are with this population of individuals. Findings from this study revealed a potentially negative impact on these students' development and academic achievement. Solutions to address the incompatibility were generated.
\end{abstract}

\section{INTRODUCTION}

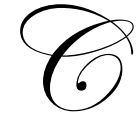

ulture plays an important role in influencing a child's process of learning and the skills that are learned. Many American Indian students' cultural heritage conflicts with mainstream school practices. At the classroom level, interactions between teachers and these students can be challenging as practices promoted by the teacher may be in direct contrast to the teachings in the students' home and the community culture. Some authors speculate that among minority groups in the U.S., the American Indians' culture has the greatest variance from the culture of mainstream society (Nel, 1993; Pichette, Garrett, Kosciulek, \& Rosenthal, 1999). Although there are many commonalities among the various American Indian groups, each group does have their own unique characteristics that influence their culture.

The research literature supports the notion that the cultural context has a significant impact on educational outcomes for minority students (Orsnstein \& Levine, 1989; Salend, Garrick Duhaney, \& Montgomery, 2002). Differences between mainstream behaviors and the home culture can contribute to the academic and social failure of the student (Cummins, 1989, Ogbu, 1987). Recent reports on the educational outcomes for American Indians seem to support that contention as demonstrated by nationwide poor graduation rates from high school (48\%; Wald, 1998), the highest dropout rates of any minority group (60 to 70\%; Shirley, 2004), and disproportionate overrepresentation in special education (13.1\%; Donovan \& Cross, 2002; U.S. Department of Education, 2000; Wald, 1998).

The issue of culturally responsive teaching is a very important special education topic. Since this population of students has one of the highest referral and placement rates for special education services, educators need to attend to this matter and seek viable solutions. Culturally responsive teaching should be a priority for pre-service and inservice instruction. School administrators as well as college and university faculty should assure teachers receive this training.

Throughout the past thirty years, many advocates for American Indian students in mainstream schools have urged teachers to use effective and culturally relevant instructional and classroom management practices (Bannon, 2004; Garrett, 1995; Nel, 1993; Pertusali, 1988; Pichette, Garrett, Kosciulek, \& Rosenthal, 1999; Youngman \& Sardongei, 1974). These practices require that teachers demonstrate a level of knowledge of cultural differences, and the willingness to adopt new strategies and concepts that meet the academic and social needs of culturally diverse students. Culturally responsive education recognizes and addresses students' various learning styles and the unique teachings and cultural influences that come from the students' family and community. 
Learning Style and Cooperative Learning Experiences. A learning style is the way an individual uses strategies to help learn tasks and the way the individual organizes the information (Riding \& Rayner, 1998). Research supports that many American Indian children tend to have a more global cognitive style of organizing information and an emphasis on using visual strategies and mental representations for processing information (Hilberg \& Tharp, 2002; Vasquez, 1990). This process allows individuals time to understand an event from beginning to end, mentally visualize key events on a gradual basis, and develop conclusions about the events from a holistic perspective.

The traditional value of reflection supports the process of developing a holistic perspective. McCarthy and Benally (2003) reported that many American Indian children tend to wait six to ten seconds to respond to an interaction. This is a sharp contrast to non American Indian children whose wait time is approximately three to five seconds for a response. This type of reflective modality is consistent with children's practice of their global perspective for processing information. This wait time allows many of these children to carefully produce an answer that is compatible with the values of inclusion, generosity, mastery, and independence (Brendtro \& Brokenleg, 1996).

This global learning style also shapes the way they collaborate and cooperate within the group. Since collaboration and cooperation is highly valued by a large number of these children, they are taught not to be opinionated or hasty in reaching conclusions. They are taught to strive to see other people's perspectives and come to a reasonable conclusion that is harmonious with others (McCarthy \& Benally, 2003). Therefore during a problem solving activity, these children would tend to favor a solution that demonstrates generosity (Brendtro \& Brokenleg, 1996) instead of egoism or self-serving actions. Cooperative learning activities as opposed to individual, competitive activities are compatible with a number of American Indian values (Butterfield \& Pepper, 1991). Students from this ethnic group learn most effectively within small groups that focus on hands-on learning in activity-based contexts. For example, McCarthy and Benally (2003) found that a number of American Indian children learned social studies, math and science skills most effectively when they were able to work in groups using charts, maps, drawings, sculptures, and even their own artistic creations to show evidence of their knowledge.

Related to the value of collaboration and cooperation, many American Indian children are taught the importance of humility not only in regards to their own performance, but in regards to peer performance (McCarthy \& Benally, 2003). A child who witnesses a fellow classmate make an error on a question may feel highly uncomfortable to answer the same question. Plank (1994) found that students from this ethnic group are likely not to respond to a question asked of him or her in the classroom when it would appear they are trying to be competitive with their peers. Thus, a teacher may assume the child who is using silence does not know the correct response. Moreover, the silence may be interpreted as noncompliance or being disrespectful; however, a child who has been taught to display humility would feel it is inappropriate to be singled out in front of others. This silence and subsequent interpretation by the teacher may put a student at risk in the educational system and may result in an inappropriate referral to special education. A referral of this type is very concerning since the national trend for qualification for special education services is very high once an individual is referred.

Teacher Instruction and Classroom Management. It appears these values help to promote self-regulation in many American Indian children. Some research indicates that American Indians value independence and individual freedoms in contrast to dominance and discipline for obedience (Brendtro \& Brokenleg, 1996; Strand \& Peacock, 2002). A important teaching for many of these children is to respect others and to develop self-respect. Through both types of respect, children once again are encouraged to self-regulate, to solve problems and show responsibility for challenges they encounter. In many instances, young American Indian children are given training in self-management skills without rewards for good behaviors, but are encouraged to view their good behaviors as a reward in itself (Strand \& Peacock, 2002). According to the literature, it appears that an intrinsic reward, such as completing the bonus questions to achieve mastery is an excellent example of many traditional American Indians' value of self-regulation for motivation, monitoring, evaluation and reward.

In terms of taking responsibility for individual actions, discipline that is very abrasive is incompatible with gaining students' cooperation. Subtle messages that highlight the value of completing a task and why the task is of value are more appropriate. The importance of mastery is a cultural value and many of these children are encouraged to achieve a mastery level for a personal goal instead of an extrinsic reward. As noted in the literature, the 
development of self-regulatory skills is an important feature of traditional American Indian values (McCarthy \& Banally, 2003; McInerney \& McInerney, 1998; Wlodkowski, 1999). Since self-regulatory behaviors are modeled and thus promoted at an early age in young children, the acquisition of this skill emerges at an early age. According to Brendtro and Brokenleg (1996), even the youngest of children in the traditional American Indian communities are given daily tasks of responsibility. Each of these young children are nurtured to learn to manage their own behaviors and to achieve mastery.

\section{METHODOLOGY}

The research took place in a graduate course on early childhood special education led by one of the researchers. The researcher/instructor interviewed seven teachers who were enrolled in the graduate class and who also worked at a southwestern Apache reservation school. These teachers were experienced educators with the Apache population and five of the seven teachers were themselves American Indians. The teachers and the instructor were engaged in a class discussion regarding cultural responsiveness of educational practices used at the reservation school with the Apache students and their families. The instructor generated comments from the teachers on how the strategies advocated in the textbook used for the class were compatible with teachings and cultural values of the Apache community. These discussions occurred over the span of this 15 week course.

During the initial course meetings with these teachers, it became apparent that some typical educational practices (see Figures 1 and 2) were incompatible with the Apache families' cultural practices. These teachers noticed a disjuncture between their pre-service training, commonly used educational practices at their school, and their own classroom experiences and knowledge of the Apache culture.

During the remaining sessions of this course, the instructor continued to generate discussions on culturally responsive teaching within this Apache community. The instructor lead discussions with the teachers who provided specific verbal and written examples of commonly used educational practices and problems with the practices (the incompatibility) and alternative practices that could be used to meet the same educational goals but would be culturally sensitive. By the end of the semester, the instructor provided the teachers with a summary of the notes and examples they had generated. The teachers reviewed the summary list to assure accuracy. From this list, the researchers developed two sets of categories for the practices, problems, and solutions (see Figures 1 and 2).

\section{RESULTS}

The following two figures represent the findings from the interviews and class discussions with the teachers at this reservation school. The data represents information reported by the teachers on the specific Apache students in this community. Although the findings are based on Apache children and families of this community, the results are similar to those discussed in the review of literature with other American Indian populations.

\section{FIGURE 1}

\section{Learning Styles And Cooperative Learning Experiences}

Teachers tend to tell or read a story in small segments. They provide some information (a part of the whole) and then check students' comprehension with discussions, comments, and questions.

The Problem: Apache children are taught to hear all of the information and then come to a conclusion. They value seeing the "big picture" first before breaking down the information.

The Solution: Teachers can accommodate the students by exposing them to the entire story or larger segments of the story to allow students to reflect and understand the whole story and its elements. Teachers can prepare students for global understanding by using the instruction "We are going to read about... (the topic)...." 
Teachers quiz children on new skills they are learning so to assess a child's level of acquisition.

The Problem: Apache children are taught to learn through modeling and practice. As children view a model, they then proceed to learn the skill through private practice (trial and error). Children are uncomfortable in demonstrating their skill level until they have reached mastery.

The Solution: Teachers need to allow students time to privately practice learning the new skill. Teachers can request volunteers to demonstrate their acquisition of the skill. Their demonstration should be private and not be a public display.

Teachers may use artificial activities to teach concepts such as math or phonics worksheets.

The Problem: Apache children learn best from meaningful, hands-on activities that are functionally based and are being learned for a purpose. If the task is deemed beneficial, the child will be more invested in learning the task.

The Solution: Teachers should clearly explain to students the purpose of learning a skill. The skill should be meaningful to the students and clearly relate to tasks valued in everyday life. As students learn the skill, teachers should use as much as possible hands-on activities that represent the real task as opposed to drill worksheets. This process promotes a unity between teacher and students and makes the teacher a part of the group.

Teachers emphasize independent work from children within the classroom.

The Problem: Apache children are taught to work in groups for the benefit of the group. They value collaboration and utilizing a group process to accomplish tasks.

The Solution: Teachers should feel comfortable with utilizing cooperative learning activities where students are encouraged to accomplish a task together and to experience success as a group unit.

When teachers ask questions of children in the classroom, they expect a verbal response.

The Problem: Apache children are taught to be comfortable with silence. When a child does not verbally respond to a teacher, the child may be considered rude or incompetent. The child may be intentionally not responding because he or she has assessed the situation and decided it is most appropriate to be silent.

The Solution: Teachers need to become more comfortable with various students' learning styles. Some students tend to be quiet learners who focus on models and observation and use less verbalization while learning. Do not publicly address students who are quiet learners. If a student is doing fine in class and chooses not to answer, allow this silent behavior. When the student feels ready to share, he or she will. Teachers need to be cautious in interpreting a student's silence as it does not necessarily mean he or she does not know the information. Additionally, a teacher may increase the chances of a student providing a verbal response if the teacher comments on an issue as opposed to directly questioning a student.

Students are expected to answer questions in class when called upon. At times, they are expected to volunteer to answer questions in class.

The Problem: Apache children are often uncomfortable to answer questions teachers ask. To answer a question may be interpreted as being boastful or competitive with other students. This is especially true when another student failed to answer the question correctly or not at all. Additionally, if a student does not fully understand a concept or has not mastered a skill, he or she will not offer an answer. This behavior may be misinterpreted as defiant behavior. 
The Solution: When teachers ask questions of students, they should phrase it to say, What do all of you think?" or "What should we do?" When teachers assign students to group projects, students are more likely to volunteer answers that represent the group's efforts as opposed to an individual's work. Additionally, students may be more apt to volunteer their participation when they believe they have a choice of whether or not they volunteer.

Teachers ask questions of children in the classroom and their wait time for a response is generally 3-5 seconds.

The Problem: Apache children are taught the importance of reflection. They begin practicing at a very young age to think a situation through before responding or acting upon the situation. In order to do this effectively, children require extra time to allow for reflection.

The Solution: Teachers need to allow adequate time (6-10 seconds) for students to process and reflect on information. With the increased wait time, students can generate answers that represent well-thought out answers.

Teachers often "spot light" a student in the class for his or her accomplishments or good behaviors.

The Problem: Apache children are taught to exhibit humility. Putting a child on a pedestal makes him or her feel very uncomfortable. They feel this makes them look like they are better than others. This makes them appear to be competitive as children are taught to never shame others.

The Solution: Teachers should quietly and individually acknowledge a student's accomplishments. It is important to remember, however, acknowledgement is not always necessary as these students learn from an early age to monitor, evaluate, and intrinsically reward themselves. If work needs to be praised, a teacher can "spot light" a group's effort and accomplishments.

Teachers often have competitions within school activities or assignments to see who the first to get done is or who can do the task the best.

The Problem: Apache students are taught to work in unity and to help others for the benefit of the group not solely to benefit his or herself.

The Solution: Teachers should emphasize cooperative work assignments as opposed to competitive activities within the classroom. Mixed ability grouping can enhance a classroom of diverse learners.

Figure 2

\section{Teacher Instruction And Classroom Management}

Teachers may have set standards and expectations of children's behaviors in the classroom.

The Problem: Rigid teacher standards regarding students' behaviors may not allow for the cultural variances and diversity among children in the classroom. If a child does not fit the teacher's set standards, the child may appear to be overly quiet, uninterested, and/or unknowledgeable. Apache children may exhibit more silent types of behaviors than other children. Thus, these students may not meet the standards of the teacher who expects verbally responsive students.

The Solution: Teachers must feel comfortable educating a variety of students with various learning styles. Utilizing solely one type of teaching style does not fit all children's strengths and needs in learning. These students learn from models and through observation. Consequently teachers need to reinforce these strategies 
and allow students to be silent and verbalize when appropriate. Additionally, students love humor. Teachers need to learn to laugh with the students and even at themselves.

Teachers expect children to look at them when they are talking to them.

The Problem: Apache children may be taught it is disrespectful to make eye contact with an adult. This is especially true when the child is perceived to be in trouble with the adult.

The Solution: Teachers should become comfortable with students who are respecting this value. Teachers can learn to realize students are not being disrespectful to the person talking when they do not look directly at their eyes. In fact, it may be a sign from the student indicating his or her respect.

Students are expected to be verbally interactive in class activities at school.

The Problem: Apache children are taught to listen quietly \& observe adults (or whomever is teaching) while learning. Children are taught to learn from modeling.

The Solution: Since modeling and observation strategies are favored in the learning process for these students, teachers need to reinforce these strategies during class instruction and activities. Do not expect hand-raising. Instead have an open ended discussion where students may volunteer answers or comments. Usually the students will designate a leader to speak for the group

Teachers tend to monitor children's learning and progress. The teacher is the control over the child's learning process.

The Problem: Apache children are taught at a very young age to be responsible individuals. They are taught to self-monitor and self-evaluate their own behaviors.

The Solution: Teachers should encourage and reinforce students' self-monitoring skills. Teachers can acknowledge the importance of students monitoring, evaluating, and rewarding their own behaviors in the classroom. Allow the student time to reflect on misbehaviors. Give the student a sense of directing his or her own behaviors.

Teachers may rely heavily on extrinsic rewards for children in their classroom (i.e. stickers or candy).

The Problem: Apache children are taught to achieve for the intrinsic reward of accomplishment. They are taught to value success in itself not the extrinsic reward that may be given.

The Solution: Teachers should gear their practices toward reinforcing self-monitoring skills in students. Self-monitoring is the highest level of behavioral control, thus in keeping compliant with family members' teaching practices, students should view their achievements as a reward in itself. Let the students keep track of their own successes. Allowing a student to help another classmate may be highly rewarding, since it serves as a classroom reinforcement and allows the student to fulfill a cultural role.

Teachers may use delayed rewards that come at the end of the week or month.

The Problem: Apache children are most motivated to accomplish for the present day rather than for future goals.

The Solution: Teachers can encourage children to think of ways that they can use a skill in the present and model how the skill will be of future use. Teachers should also encourage self-reinforcement practices in the students to assure that delays are not interfering with learning. When students work in groups, they tend to motivate each other to learn a skill. This may help to encourage students to work for future accomplishments. 
$\checkmark \quad$ Teachers use punishment as a means to change behavior.

The Problem: Since Apache children are taught to self-monitor and self-evaluate their behaviors, they habitually assess how their behavior hurts or benefits others. Children are taught to adjust their behaviors (if needed) to benefit the group. Public scolding should not be used as it tends to degrade the student's status in front of peers and the teacher's status in regards to having respect from the student(s).

The Solution: Teachers need to continue to encourage students to self-monitor their behaviors. Through this process, students learn to adjust their behaviors when appropriate. If the adjustment does not occur, teachers should calmly explain the correct or proper conduct. Teachers need to exhibit patience and remind the student to think about being a group player. As teachers reinforce group unity, those who are not adjusting will feel like an outsider if he or she chooses to behave differently from what is appropriate.

\section{DISCUSSION}

The results of these interviews and problem solving sessions suggest that educators in this rural community are using typical teacher/student communication methods; however, many of these methods are culturally insensitive to the Apache students and families. The typical approaches taught in teacher preparation programs are not the most effective strategies to use with this Apache population and also with many other American Indian groups (Emmer \& Stough, 2001; McCarthy \& Banally, 2003; Wlodkowski, 1999; Wlodkowski \& Ginsberg, 1995). The results indicate that the use of these practices may hinder or jeopardize the student's learning and academic achievement. Additionally, typical educational practices used with American Indian children may create feelings of isolation, anxiety, and rejection (Luftig, 1983), as the practices are incompatible with the teachings and values of their families. Although this study focused on the Apache population, results of this study reflected the findings of many other studies on the learning process of other American Indian groups.

Figure 1 shows that teachers from this community continue to teach the Apache students using small story segments, quizzing students on parts of the whole and requiring individual work from students. These teaching strategies are not compatible with the learning style the families have promoted during the rearing of the child. It is quite possible that changing these teaching strategies in accordance with the solutions provided in this article could improve a student's learning and skill acquisition.

Consistent with other reports (Guilmet, 1976; Pewewardy, 2002; Plank, 1994), the discussions with the teachers revealed that Apache children are more likely to engage in silent observations as they visually process information rather than verbalize knowledge as they process the information. As seen in Figure 1, these students became reflective of a whole concept as opposed to analyzing small pieces of information. This reflection process allows the individual time to clearly think about a response prior to responding as opposed to sharing their first impulse of thought. This finding in this study was very similar to other studies on other American Indian groups that focused on the reflective style of processing students use. This is an important learning characteristic of many American Indian students that teachers should become aware of so to enhance these students' educational achievements.

As shown in Figure 1, teachers should embrace group work and non-competitive teaching practices when working with these Apache children. A teaching approach that develops group oriented classrooms and avoids a focus on individual students would be much more successful with these students. Additionally, when students are learning new skills, the skills should have relevance to the student's group and not for the sole gain of the individual.

The quiet and unassuming nature of many American Indian students as found by other researchers, is characterized by periods of quiet thinking. The students will look down when being instructed and use observation for an extended period of time to learn a new skill. These behaviors are noted in Figure 1 and suggest that their learning patterns are quite different from more traditional students in the schools. These behaviors should be reinforced by teachers and not be seen as a learning deficit but as a learning strategy. 
In terms of behavior management, teachers from this community continue to monitor students' learning and do not utilize the natural self-monitoring style many of these children have been taught to use. Figure 2 shows that these teachers continue to provide extrinsic rewards, use delayed reinforcements, and administer punishments as a way to change behaviors. These strategies do not match the cultural value of these students and will most likely impede the learning of the child.

Overall, this study stresses the importance of teachers learning about the cultural characteristics of their students and their families. This is particularly important with American Indian students, as was noted earlier, the American Indian's culture has the greatest variance of all minority populations from the culture of the mainstream society. Although there are similarities between American Indian groups, it is important for teachers to understand the learning styles of students from their community as learning styles will vary from one community to another. This knowledge a teacher attains can become a valuable tool to assist in educating a culturally diverse population of students. Traditional university and college programs can tailor courses with a focus on the importance of cultural differences, culturally responsive teaching, as well as providing experiences in using the strategies that address preferred learning styles. To further this process, school districts should regularly in-service their teachers in regards to these issues. Finally, the individual educator must take the additional time to develop rapport, trust and community acceptance of the families they serve.

Teachers should develop a new sense about the way they approach the American Indian child and their families. The literature has, for years, focused on good practices for teachers to use with the American Indian populations (Berry, 1969; Wilson \& Black, 1978), however, teachers continue to teach American Indian students using practices that are incompatible with the families' rearing practices. These authors have called on teachers to move away from cultural immersion practices learned in their teacher preparation programs. Teachers are encouraged to become knowledgeable of the students' learning characteristics and become flexible and willing to alter planned strategies and teaching practices to better match the learning styles of their students (see Figures 1 and 2). These strategies can enrich not only the education of the American Indian population but other culturally diverse groups of students.

This study highlights the culturally sensitive practices supported by a host of educational advocates for American Indian children for the past three decades (Bannon, 2004; Garrett, 1995; Nel, 1993; Pertusali, 1988; Pichette, Garrett, Kosciulek, \& Rosenthal, 1999; Youngman \& Sardongei, 1974). The concerning issue and major point for readers to consider is that the educational systems appear to have done very little to change the manner in which teachers are interacting with their American Indian students and their families. Thus, training agencies, inservice delivery, and other teacher preparation programs should focus on using the solutions to the commonly known problems discussed in this article. Without this type of attention, the field will continue to re-visit this issue. While this occurs, the success rate for a large segment of American Indian children will continue to reproduce the same disturbing results. We will continue to see high drop out rates, low graduation rates from high school, and a disproportionate over representation of American Indian students in special education programs. This is a particular critical issue for rural schools serving this population and their families. Many of these families have maintained their traditional values and continue to pass these values on through the generation of families. These cultural beliefs and values are subtly engrained through teachings and experiences within their family and community systems. If our education system is culturally unresponsive to these values, the educational impact may be devastating. 


\section{REFERENCES}

1. Bannon, T. K. (2004). Reaching children through their ancestral language and authentic literature. Reclaiming Children and Youth, 12(4), 232-236.

2. Berry, B. (1969). The education of American Indians. Washington, DC: US. Government Printing Office.

3. Brendtro, L. K. \& Brokenleg, M. (1996). Beyond the Curriculum of Control. Journal of Correctional Education, 47(4), 160-166.

4. Butterfield, R. \& Pepper, F. (1991). Improving participation in elementary and secondary education for American Indian and Alaskan Native students. (ERIC Document Reproduction Service No. ED 343 763).

5. Cummins, J. (1989). Empowering minority students. Sacramento, CA: California Association of Bilingual Education.

6. Donovan, S. \& Cross, C. (Eds.). (2002). Minority students in special and gifted education. Washington, DC: National Academy Press.

7. Emmer, T. E. \& Stough, M. L. (2001). Classroom management: A critical part of educational psychology, with implications for teacher education. Educational Psychologist, 36(2), 103-112.

8. Hilberg, R. S. \& Tharp, R. G. (2002). Theoretical perspective, research findings, and classroom implications of the learning styles of American Indian and Alaska Native Students. Eric Digests: Special Edition, Indian Edu/Research.Net. (EDO-RC-03-6).

9. Garrett, M. T. (1995). Between two worlds: Cultural discontinuity in the dropout of Native American youth. The School Counselor, 42, 186-195.

10. Guilmet, G. M. (1976). The nonverbal American Indian child in the classroom: A survey. (ERIC Document Reproduction Service No. Ed 255 336)

11. Luftig, R. L. (1983). Effects of schooling on the self-concept of Native American students. School Counselor, $30,251-260$.

12. McCarthy, J. \& Banally, J. (2003). Classroom management in a Navajo Middle School. Theory Into Practice, 42(4), 296-305.

13. McInerney, M. D. \& McInerney, V. (1998). The goals of schooling in culturally diverse classrooms. Clearing House, 71(6), 363-367.

14. Nel, J. (1993). Preventing school failure: The Native American child. Preventing School Failure, 37(3), 19-25.

15. Ogbu, J. (1987). Variability in minority school performance: A problem in search of an explanation. Anthropology and Education Quarterly, 18, 312-334.

16. Ornstein, A. C. \& Levine, D. U. (1989). Social class, race, and school achievement: Problems and prospects. Journal of Teacher Education, 4(5), 17-23.

17. Pertusali, L. (1988). Beyond segregation or integration: A case study from effective Native American Education. Journal of American Indian Education, 27, 10-20.

18. Pewewardy, C. (2002). Learning styles of American Indian Alaska native students: A review of the literature and implications for practice. Journal of American Indian Education, 41(3), 22-56.

19. Pichette, F. E., Garrett, T. G., Kosciulek, F. J., \& Rosenthal, A. D. (1999). Cultural identification of American Indians and its impact on rehabilitation services. Journal of Rehabilitation, 65(3), 3-11.

20. Plank, G. A. (1994). What silence means for educators of American Indian children. Journal of American Indian Education, 34, 3-19.

21. Riding, R. \& Rayner, S. (1998). Cognitive Styles and Learning Strategies: Understanding Style Differences in Learning and Behavior. London: David Fulton Publishers.

22. Salend, J. S., Garrick Duhaney, M. L., \& Montgomery, W. (2002). A comprehensive approach to identifying and addressing issues of disproportionate representation. Remedial and Special Education, 23(5), 289-300.

23. Shirley, J. V. (2004). On the right path. Black Issues in Higher Education, 21(9), 88-92.

24. Simpson, R. L. (1996). Working with parents and families of exceptional children and youth ( $3^{\text {rd }}$ ed.). Austin: TX: Pro-ed.

25. Strand, J. A. \& Peacock, T. D. (2002). Nurturing resilience and school success in American Indian and Alaska Native students. ERIC Digests: Clearinghouse on Rural Education and Small Schools. (EDO-RC-02-11).

26. U.S. Department of Education. 2000. Twenty-second annual report to Congress on the implementation of the Individuals with Disabilities Education Act. Washington, DC: Author. 
27. Vasquez, J. A. (1990). Teaching to the distinctive traits of minority students. The Clearing House, 63, 299304.

28. Wald, J. (1998).Culturally and linguistically diverse professionals in special education: A graphic analysis. Reston, VA: Council for Exceptional Children.

29. Wilson, J. G. \& Black, A. B. (1978). Native American Indians and variables that are interrelated with academic achievement. Paper presented in the annual meeting of the American Educational Opportunities Program Personnel, Fontana, WI.

30. Wlodkowski, J. R. (1999). Motivation and diversity: A framework for teaching. New Directions for Teaching \& Learning, 78, 7-17.

31. Wlodkowski, J. R. \& Ginsberg, M.B. (1995). A framework for culturally responsive teaching Educational Leadership, 53(1), 17-21.

32. Youngman, G. \& Sadongei, M. (1974). Counseling the American Indian child. Elementary School Guidance And Counseling, 8, 273-277.

\section{NOTES}

